\title{
PERENCANAAN CAMPURAN BETON MENGGUNAKAN SUBSTITUSI SEMEN DENGAN ABU TERBANG DAN ZAT ADDITIVE SUPERPLACTIZER
}

\author{
Tri Octaviani, ST. (Alumni Teknik Sipil) \\ Muhamad Ryanto, ST., M.T (Dosen Teknik Sipil) \\ Jurusan Teknik Sipil - Fakultas Teknik, Universitas Sangga Buana YPKP Bandung
}

\begin{abstract}
ABSTRAK
Komposisi campuran superplasticizer yang digunakan dalam penelitian ini adalah $0,2 \%$ untuk semua variasi dan subtitusi dengan abu terbang (fly ash) sebanyak $0 \%, 20 \%, 25 \%, 30 \%, 35 \%$ dan $40 \%$ dari berat semen. Benda uji yang digunakan adalah benda uji kubus $15 \mathrm{~cm}$ x $15 \mathrm{~cm}$ x $15 \mathrm{~cm}$, kuat tekan beton yang direncanakan 26,49 MPa yang diuji pada umur 21 hari dilakukan perawatan sebelum pengujian. Pengujian kuat tekan ini menggunakan spesimen kubus sebanyak 12 benda uji yang terdiri dari 6 tipe spesimen dimana masingmasing specimen sebanyak 2 benda uji.

Dari percobaan kuat tekan diadapati kuat tekan beton yang tertinggi pada campuran beton penggunaan abu terbang sebanyak 35\% yaitu sebesar 41.01 MPa sedangkan kuat tekan beton yang terendah dengan campuran beton abu terbang sebanyak 40\% yaitu sebesar $23.00 \mathrm{MPa}$. Penggunaan substitusi pemakaian abu terbang $35 \%$ didapati kuat tekan lebih tinggi dibandingkan dengan beton variasi campuran abu terbang lainnya. Adukan dengan abu terbang tentu membantu kinerja mekanis beton karena abu terbang mempunyai butiran yang halus dan sebagai pengisi pori-pori pada beton.
\end{abstract}

Kata Kunci : abu terbang, subtitusi, kuat tekan, superplaticizer.

\section{PENDAHULUAN}

\section{Latar Belakang}

Secara umum bahan pengisi (filler) beton yang dipakai mempunyai karakteristik yang dapat memperbaiki kinerja beton seperti keawetan (durability) serta kekuatan (strength) yang dapat diperlukan untuk konstruksi. Bahan filler dapat menjadikan beton sebagai bahan alternatif pengganti semen dapat dikembangkan baik bentuk fisik maupun metode pelaksanaannya.

Peningkatan mutu kuat tekan beton dapat dilakukan dengan mensubstitusikan penggunaan semen dari beberapa bahan substitusi pengisi material beton diantaranya adalah abu terbang (fly ash) selain dapat meningkatkan mutu beton, juga dapat mempengaruhi tegangan dan regangan pada beton. Fly Ash adalah limbah dari hasil proses pembakaran batubara yang keluar dari tungku pembakaran.

Dalam penelitian ini juga digunakan bahan tambah Admixture Additive Concrete, yaitu bahan tambah yang dapat memperbaiki kelecakan campuran beton (workability) sehingga memudahkan untuk diaduk, dituang, diangkut dan dipadatkan pada proses pembuatan beton segar. Dengan menambahkan zat aditif berupa superplasticizer ke dalam campuran beton diharapkan dapat meningkatkan nilai kelecakan campuran beton.

\section{Rumusan Masalah}

Rumusan masalah yang akan diteliti sebagai berikut :

1. Menguji kuat tekan beton dengan penambahan Superplasticizer (Sikacim) 
dengan menguragi jumlah semen dengan substitusi material abu terbang.

2. Mengkaji pengaruh dengan penambahan penggunaan zat aditif admixture seperti Superplasticizer (Sikacim) pada campuran akibat pengurangan jumlah semen disubstitusi dengan abu terbang terhadap nilai kelecakan dan slump untuk menentukan proporsi terhadap campuran beton normal.

3. Mengkaji peningkatan kekuatan beton pada umur 21 hari dengan mengunakan variasi penggunaan jumlah kadar abu terbang campuran beton.

\section{TINJAUAN PUSTAKA}

Peningkatan mutu kuat tekan beton dapat dilakukan dengan menambahkan bahan admixture, yaitu dengan menggunakan admixture mineral berupa abu terbang (fly ash) dan chemical superplasticizer (Sikacim).

\section{Abu Terbang (Fly Ash)}

Abu terbang sebagai bahan pozzolan mempunyai ketahanan terhadap agresi sulfat dan air kotor. Bahan ini digunakan untuk penambah atau pengganti sampai $70 \%$ semen. Bukti-bukti yang ada menunjukkan bahwa kekuatan batas dengan mengganti sekurangkurangnya $20 \%$ dari semen dengan pozzolan hampir tak beda dengan bila semen saja yang digunakan. Penggunaan abu terbang telah banyak digunakan sebagai campuran beton. Pemanfaat material abu terbang (fly ash) sudah banyak dimanfaatkan pada pabrik pembuata semen sebagai bahan substitusi batuan trass dengan memasukkannya pada campuran pembuatan semen dibagian proses cement mill dengan menggunakan udara tekan (pneumatic system). Disamping dimanfaatkan di industri semen, pemanfaatan abu terbang dapat juga dimanfaatkan menjadi campuran beton pracetak dan dicetak menjadi paving blok/batako.

\section{Zat Aditif Superplasticizer}

Superplasticizer (Sikacim) adalah bahan tambahan kimia (chemical admixture) yang dapat melarutkan gumpalan-gumpalan dengan cara melapisi pasta semen sehingga semen dapat tersebar dengan merata pada adukan beton dan mempunyai pengaruh dalam meningkatkan kelecakan beton sampai pada tingkat yang cukup tinggi. Bahan ini digunakan dalam jumlah yang relatif sedikit bila penggunaan dosis dalam jumlah banyak akan dapat meningkatnya terjadinya proses bleeding. Superplasticizer dapat mereduksi jumlah penggunan air sampai $15 \%$ dari campuran awal.

Beton berkinerja tinggi dapat dihasilkan dengan pengurangan jumlah volume air terhadap semen, akibat pengurangan kadar air akan membuat campuran lebih padat sehingga pemakaian superplasticizer sangat diperlukan untuk mempertahankan nilai slump yang tinggi.

\section{Slump Test}

Pengujian ini bertujuan untuk melakukan penentuan nilai kelecakan berupa kekentalan (viscocity) / plastisitas beton segar dengan mengukur nilai kemerosotan beton segar setelah dipadatkan dengan alat abraham 
kerucut. Nilai Slump Test adalah besaran kemerosotan dan kohesif dari beton segar.

\section{Pengujian Kuat Tekan Beton}

Nilai kuat tekan beton didapatkan melalui tata cara pengujian standar, menggunakan mesin uji tekan dengan cara memberikan beban tekan bertingkat dengan kecepatan peningkatan beban tertentu dengan benda uji specimen berupa silinder atau kubus. Selanjutnya benda uji ditekan dengan mesin uji tekan sampai pecah. Beban tekan maksimum pada saat benda uji pecah dibagi luas penampang benda uji merupakan nilai kuat tekan beton yang dinyatakan dalam MPa atau $\mathrm{kg} / \mathrm{cm}^{2}$. Tata cara pengujian yang umum dipakai mengikuti Standar aturan ASTM C39 atau PBI 1989.

Formula perhitungan kuat tekan beton adalah:

$$
f^{\prime} c=\frac{P}{A}
$$

Keterangan

$f^{\prime} c$ : Kuat Tekan Beton

P : Beban Maksimum

A : Luas Penampang

\section{METODOLOGI PENELITIAN}

Metode ACI (American Concrete Institute)

211.1-91 Standard Practice for Selecting Proportions for Normal Heavyweight and Mass Concrete (Reapproved 2002) mensyaratkan suatu campuran perancangan beton dengan mempertimbangkan sisi ekonomisnya dengan memperhatikan ketersediaan bahan-bahan di lapangan, serta kemudahan pelaksanaan pekerjaan, serta keawetan, kekuatan dan pekerjaan beton.
Cara ACI mempertimbangkan dengan ukuran agregat tertentu, jumlah air perkubik akan menentukan tingkat konsistensi dari campuran beton yang pada akhirnya akan mempengaruhi pelaksanaan pekerjaan kelecakan (workability) campuran beton.

\section{Flow Chart Penelitian}

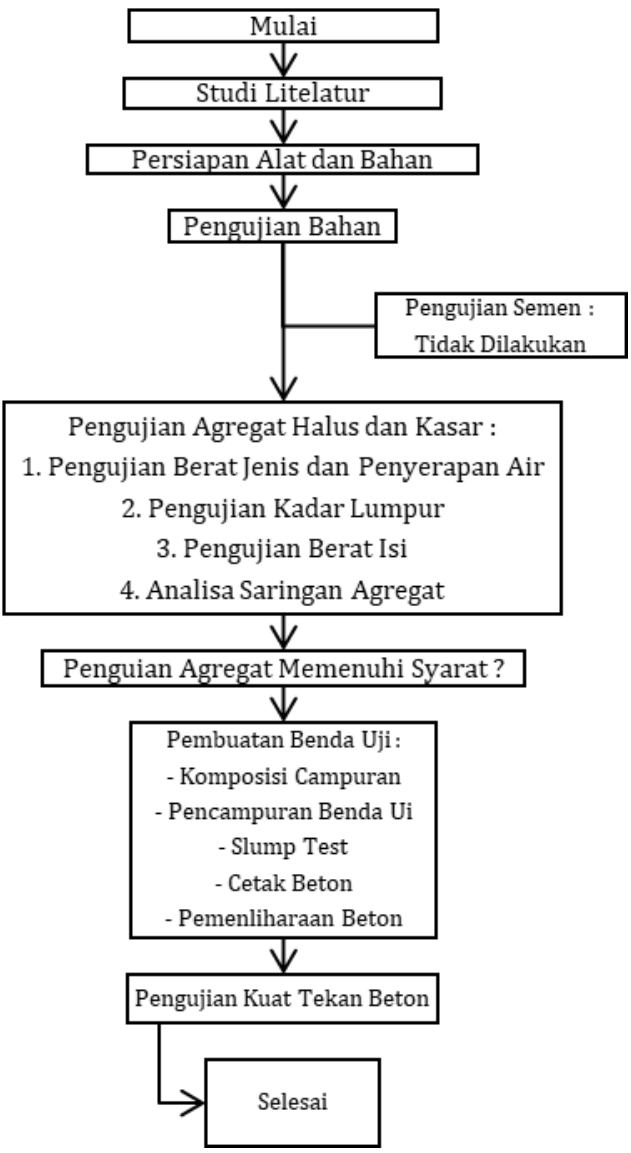

\section{HASIL DAN PEMBAHASAN}

\section{Pengujian Agregat}

Adapun hasil dari pengujian agregat diantaranya sebagai berikut :

- Diameter maksimum agregat kasar = $19.00 \mathrm{~mm}$

- Berat Jenis dan Penyerapan Air $=2.57$ $\%$

- Berat Isi $=1.620 \mathrm{gr} / \mathrm{cm}^{3}$, 


\section{Pengujian Agregat Halus}

- FM Agregat Halus $=2.985 \mathrm{~mm}$

- Berat Jenis dan Penyerapan Air = $2.72 \%$.

- Berat Isi Padat $=1.44 \mathrm{gr} / \mathrm{cm} 3$

- Kadar Lumpur $=1.46 \%$

\section{Pembuatan Benda Uji}

Rencana campuran beton yang akan dibuat pada penelitian ini menggunakan perbandingan jumlah semen, batu pecah, dan pasir. Agregat yang digunakan adalah agregat kasar yang lolos saringan 3/4 “ (19.00 mm), agregat halus yang lolos saringan No.4 (4,75 $\mathrm{mm})$, namun tertahan pada saringan No.4 $(4,75 \mathrm{~mm})$ dan menggunakan semen tiga roda tipe 1 .

Dalam penelitian ini dibuat benda uji beton normal sebanyak 2 spesimen sebagai pembanding. Benda uji beton lainnya dengan pengunaan abu terbang dan superplasticizer.

Tabel 1. Spesimen Benda Uji

\begin{tabular}{|c|c|c|c|c|c|}
\hline No. & $\begin{array}{c}\text { Kode Benda } \\
\text { Uji }\end{array}$ & PC & Fly Ash & $\begin{array}{c}\text { Super } \\
\text { Plasticizer }\end{array}$ & Jumlah \\
\hline 1 & BN & $100 \%$ & - & $0.20 \%$ & 2 \\
\hline 2 & BP 20 & $80 \%$ & $20 \%$ & $0.20 \%$ & 2 \\
\hline 3 & BP 25 & $75 \%$ & $25 \%$ & $0.20 \%$ & 2 \\
\hline 4 & BP 30 & $70 \%$ & $30 \%$ & $0.20 \%$ & 2 \\
\hline 5 & BP 35 & $65 \%$ & $35 \%$ & $0.20 \%$ & 2 \\
\hline 6 & BP 40 & $60 \%$ & $40 \%$ & $0.20 \%$ & 2 \\
\hline \multicolumn{7}{|c|}{ Jumlah Total } \\
\hline
\end{tabular}

\section{Pengujian Slump Test}

Hasil pengukuran slump test setiap benda uji.

Tabel 2. Nilai Kemerosotan Slump

\begin{tabular}{|c|c|c|}
\hline $\begin{array}{c}\text { Kode Benda } \\
\text { Uji }\end{array}$ & $\begin{array}{c}\text { Slump } \\
(\mathrm{cm})\end{array}$ & Keterangan \\
\hline $\mathrm{BN}$ & 11 & Beton Normal \\
\hline BP 20 & 9.5 & $\begin{array}{c}\text { Beton Fly Ash } 20 \%+ \\
\text { Superplasticizer } 2 \%\end{array}$ \\
\hline BP 25 & 8 & $\begin{array}{c}\text { Beton Fly Ash } 25 \%+ \\
\text { Superplasticizer } 2 \%\end{array}$ \\
\hline BP 30 & 8.5 & $\begin{array}{c}\text { Beton Fly Ash } 30 \%+ \\
\text { Superplasticizer } 2 \%\end{array}$ \\
\hline BP 35 & 7.8 & $\begin{array}{c}\text { Beton Fly Ash } 35 \%+ \\
\text { Superplasticizer } 2 \%\end{array}$ \\
\hline BP 40 & 8 & $\begin{array}{c}\text { Beton Fly Ash } 40 \%+ \\
\text { Superplasticizer } 2 \%\end{array}$ \\
\hline
\end{tabular}




\section{Pengujian Kuat Tekan}

Pengujian dilakukan pada umur beton ke 14 dan ke 21 hari dan sebelum pengujian dilakukan proses perawatan beton dengan cara perendaman.

Tabel 3. Nilai Kuat Tekan Benda Uji Umur 21 Hari

\begin{tabular}{|c|c|c|c|c|c|c|c|}
\hline No. & Kode Benda Uji & $\begin{array}{c}\text { Berat } \\
\text { Benda Uji } \\
(\mathbf{K g})\end{array}$ & $\begin{array}{c}\text { Berat Jenis } \\
\text { Benda Uji } \\
(\mathbf{K g} / \mathbf{m 3})\end{array}$ & $\begin{array}{c}\text { Luas } \\
\text { Bidang } \\
(\mathbf{m m})\end{array}$ & $\begin{array}{c}\text { Beban } \\
(\mathbf{k N})\end{array}$ & $\begin{array}{c}\text { Kuat } \\
\text { Tekan } \\
\text { Beton } \\
(\mathbf{k g} / \mathbf{c m})\end{array}$ & $\mathbf{F c})$ \\
\hline 1 & BN & $(\mathbf{M P a})$ & \\
\hline 2 & BP 20 & 7.7 & 2281.48 & 22.5 & 790 & 357.91 & 30.28 \\
\hline 3 & BP 25 & 7.8 & 2311.11 & 22.5 & 840 & 380.56 & 32.20 \\
\hline 4 & BP 30 & 7.6 & 2311.11 & 22.5 & 1000 & 453.05 & 38.33 \\
\hline 5 & BP 35 & 7.6 & 2251.85 & 22.5 & 880 & 398.69 & 33.73 \\
\hline 6 & BP 40 & 7.9 & 2340.75 & 22.5 & 1070 & 484.77 & 41.01 \\
\hline
\end{tabular}

Tabel 4. Nilai Konversi Kuat Tekan 21 Hari $\rightarrow 7$ Hari

\begin{tabular}{|c|c|c|c|c|c|}
\hline No. & Kode Benda Uji & $\begin{array}{c}\text { Umur } \\
\text { (Hari) }\end{array}$ & $\mathbf{f ' c}^{\prime} \mathbf{c}$ (MPa) & $\begin{array}{c}\text { Faktor Konversi } \\
\text { 7 Hari }\end{array}$ & f'c (MPa) \\
\hline 1 & BN & 7 & 30.28 & 0.7 & 22.08 \\
\hline 2 & BP 20 & 7 & 32.20 & 0.7 & 23.48 \\
\hline 3 & BP 25 & 7 & 38.33 & 0.7 & 27.95 \\
\hline 4 & BP 30 & 7 & 33.73 & 0.7 & 24.60 \\
\hline 5 & BP 35 & 7 & 41.01 & 0.7 & 29.91 \\
\hline 6 & BP 40 & 7 & 23.00 & 0.7 & 16.77 \\
\hline
\end{tabular}

Tabel 5. Nilai Konversi Kuat Tekan 21 Hari $\rightarrow 14$ Hari

\begin{tabular}{|c|c|c|c|c|c|}
\hline No. & Kode Benda Uji & $\begin{array}{c}\text { Umur } \\
\text { (Hari) }\end{array}$ & $\mathbf{f}^{\prime} \mathbf{c}(\mathbf{M P a})$ & $\begin{array}{c}\text { Faktor Konversi } \\
\text { 14 Hari }\end{array}$ & f'c (MPa) \\
\hline 1 & BN & 14 & 30.28 & 0.88 & 27.76 \\
\hline 2 & BP 20 & 14 & 32.20 & 0.88 & 29.52 \\
\hline 3 & BP 25 & 14 & 38.33 & 0.88 & 35.14 \\
\hline 4 & BP 30 & 14 & 33.73 & 0.88 & 30.92 \\
\hline 5 & BP 35 & 14 & 41.01 & 0.88 & 37.60 \\
\hline 6 & BP 40 & 14 & 23.00 & 0.88 & 21.08 \\
\hline
\end{tabular}

Tabel 6. Nilai Konversi Kuat Tekan 21 Hari $\rightarrow 28$ Hari

\begin{tabular}{|c|c|c|c|c|c|}
\hline No. & Kode Benda Uji & $\begin{array}{c}\text { Umur } \\
\text { (Hari) }\end{array}$ & $\mathbf{f}^{\prime} \mathbf{c}(\mathbf{M P a})$ & $\begin{array}{c}\text { Faktor Konversi } \\
\text { 28 Hari }\end{array}$ & f'c (MPa) \\
\hline 1 & BN & 28 & 30.28 & 1.00 & 31.54 \\
\hline 2 & BP 20 & 28 & 32.20 & 1.00 & 33.54 \\
\hline 3 & BP 25 & 28 & 38.33 & 1.00 & 39.93 \\
\hline 4 & BP 30 & 28 & 33.73 & 1.00 & 35.14 \\
\hline 5 & BP 35 & 28 & 41.01 & 1.00 & 42.72 \\
\hline 6 & BP 40 & 28 & 23.00 & 1.00 & 23.96 \\
\hline
\end{tabular}

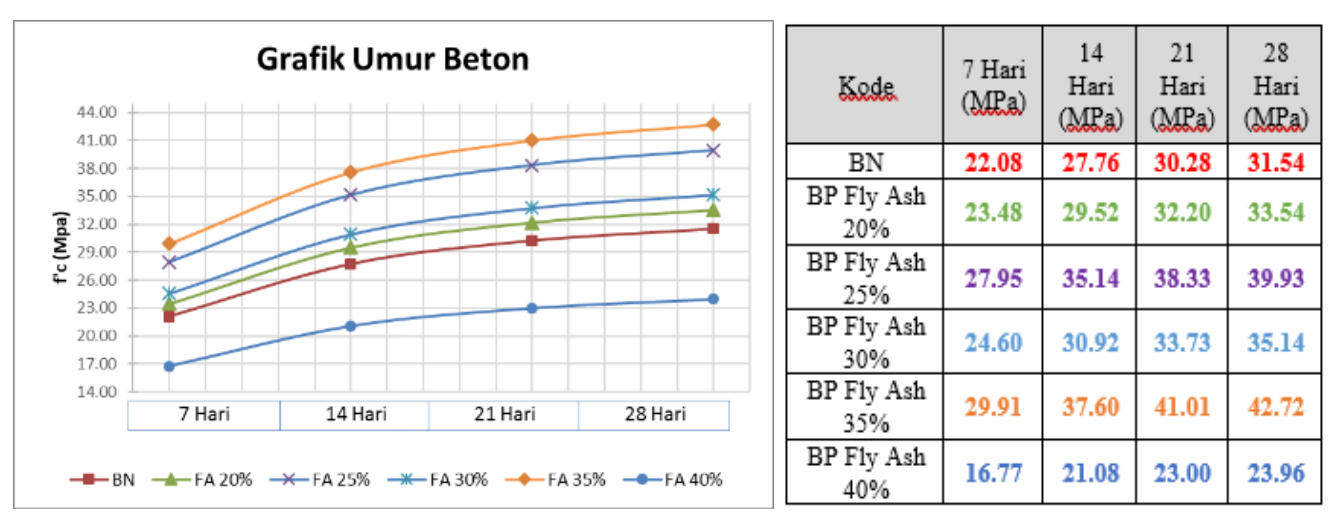

Gambar 1. Grafik Kuat Tekan Beton 


\section{KESIMPULAN}

Berdasarkan hasil pengujian didapati

kesimpulan sebagai berikut :

1. Beton dengan campuran abu terbang (fly ash) sebanyak 35\% dari semen dan $2 \%$ campuran superplasticizer setelah dilakukan uji kuat tekan pada usia 21 hari memiliki nilai kuat tekan yang tinggi yaitu 41,01 $\mathrm{MPa}$ setara 42.72 MPa untuk usia 28 hari.

2. Beton dengan campuran abu terbang (fly ash) 35\% mendapatkan nilai kuat tekan yang paling tinggi yaitu 41.01 Mpa pada usia 21 hari setara 42.72 MPa untuk usia 28 hari dan melebihi dari target yang di rencanakan yaitu 26.49 MPa.

3. Dalam penelitian ini bahan substitusi abu terbang (fly ash) paling optimal dalam penelitian ini dengan kadar substitusi semen sebanuak 35\%.

4. Beton dengan campuran abu terbang (fly ash) 40\% dengan memperoleh kuat tekan yang rendah.

\section{SARAN}

Dari uraian kesimpulan di atas dengan merujuk pembahasan dan hasil penelitian :

1. Perlu diadakan lagi penelitian lebih lanjut terkait beton yang dengan kadar abu terbang (fly ash) lebih dari $35 \%$. Karena adanya penambahan berlebih material abu terbang menyebabkan kuat tekan yang di hasilkan beton rendah dibanding dengan pemakaian beton normal.
2. Ada baiknya beton dengan menggunakan abu terbang (fly ash) jangan terlalu banyak karena abu terbang tersebut tidak akan mengikat erat tanpa bantuan semen, semakin berkurang semen maka semakin renggang ikatan abu terbang terhadap campuran dan kuat tekan semakin rendah.

\section{DAFTAR PUSTAKA}

American Concrete Institute, ACI 211.1.91 Standard Practice for Selecting Proportions for Normal, Heavyweight, and Mass Concrete, Reaproved 2002, Reported by ACI Committee 211. USA : PCA, 2002

Aulia Ziaulhaq. Teknologi Bahan I. Program SP-4 Jurusan Teknik Sipil. Politeknik Negeri Jakarta : 2012.

Departemen Pekerjaan Umum. Metode Pengujian Kadar Agregat. SNI 03 1971 : 1990. Badan Standarisasi Nasional, Jakarta : 1990.

Departemen Pekerjaan Umum. Tata Cara Pembuatan dan Perawatan Benda Uji Beton di Labolatorium. SNI 2493 2011. Badan Standarisasi Nasional, Jakarta : 2011.

Departemen Pekerjaan Umum. Tata Cara Pembuatan Kaping untuk Benda Uji Silinder Beton. SNI 6369 : 2008. Badan Standarisasi Nasional, Jakarta : 2008.

Departemen Pekerjaan Umum. Metode Pengujian Slump Beton. SNI 03 1972 : 1990. Badan Standarisasi Nasional, Jakarta : 1990.

Departemen Pekerjaan Umum. Metode Pengujian Jumlah Bahan Dalam Agregat Yang Lolos Saringan No.200. SNI 03-4142-1996. Badan Standarisasi Nasional, Jakarta : 1996. 
Departemen Pekerjaan Umum. Semen Portland. SNI-15-2049 : 2004. Badan Standarisasi Nasional, Jakarta : 2004

Departemen Pekerjaan Umum. Tata Cara Pembuatan Rencana Campuran Beton Normal. SNI 03-2834 : 2000. Badan Standarisasi Nasional, Jakarta 2000.

Dwi Kusuma, Peranan Air Dalam Pembuatan Beton. Jakarta : 2012

Ir. Muhammad Ryanto, MT. Teknologi Bahan Beton. Perencanaan Campuran Beton. Jurusan Teknik Sipil Universitas Sangga Buana YPKP . Bandung : 2014
Perpustakaan Prosida, 1971. Penjelasan \& Pembahasan mengenai Peraturan Beton Indonesia. Departemen Pekerjaan Umum dan Tenaga Listrik, Lembaga Penjelidikan Masalah Bangunan, Bandung, 1971.

Tika Oktaria, 2013. Durabilitas Beton dengan Subtisusi Sebagian Semen dengan Abu Sekam Padi. Teknik Sipil, Universitas Pendidikan Indonesi, Bandung : 2013.

Tjokrodimuljo, $\quad$ Kardiyono. 2007. TEKNOLOGI BETON, Jurusan Teknik Sipil. Fakultas Teknik Universitas Gadjah Mada, Yogyakarta : 2007.

Tri Mulyono. Teknologi Beton. Jakarta : 2005 